\title{
Oral lichen planus: two case reports in male patients
}

\section{Líquen plano oral: relato de dois casos em pacientes masculinos}

\begin{abstract}
Purpose: Lichen planus is a chronic systemic disease that commonly involves the mucosa of the oral cavity, most often in the absence of skin lesions. Although relatively frequent, oral lichen planus is the target of much controversy, mainly in relation to its pathogenesis and possible potential for malignancy. Thus, the objective of this paper is to report two cases of lichen planus in male patients and to discuss the main aspects of this disease in relation to etiopathogenesis and treatment.

Case description: Physical and histopathological examinations were carried out to confirm the diagnosis of oral lichen planus. An elixir of dexamethasone was prescribed in the first case, and in the second case, topical $0.05 \%$ clobetasol propionate was prescribed. After fifteen days, both patients presented regression of the lesion.

Conclusion: Although the occurrence of oral lichen planus is common, an accurate diagnosis is necessary so that the correct treatment can be established.
\end{abstract}

Key words: Lichen planus; oral mucosa; pathogenesis; diagnosis; treatment

\section{Resumo}

Objetivo: $O$ líquen plano é uma doença crônica sistêmica comum que envolve a mucosa oral, na maioria das vezes na ausência de lesões em pele. Embora relativamente comum, o líquen plano oral é alvo de muita controvérsia, especialmente em relação à sua patogênese e possibilidade de uma eventual transformação maligna. Assim, o objetivo deste trabalho é relatar dois casos de líquen plano em pacientes do sexo masculino e discutir os principais aspectos dessa lesão em relação a etiopatogênese e tratamento.

Descrição do caso: Exames físicos e histopatológicos foram realizados para confirmar o diagnóstico de líquen plano oral. Foi prescrito elixir de dexametasona no primeiro caso e no segundo caso, foi prescrito o uso tópico de propionato de clobetasol 0,05\%. Após quinze dias, os pacientes retornaram com regressão da lesão.

Conclusão: Embora a ocorrência de líquen plano oral é comum, o diagnóstico preciso é necessário para que o correto tratamento possa ser realizado.

Palavras-chave: Líquen plano; mucosa oral; patogênese; diagnóstico; tratamento

\section{Maiara de Moraes a \\ Felipe Rodrigues de Matos ${ }^{\circ}$ \\ Joabe dos Santos Pereira a \\ Ana Myriam Costa de Medeiros ${ }^{a}$ \\ Éricka Janine Dantas da Silveira ${ }^{\circ}$}

\begin{abstract}
a Post-Graduate Program, Oral Pathology, Federal University of Rio Grande do Norte, Natal, RN, Brazil
\end{abstract}

\author{
Correspondence: \\ Éricka Janine Dantas da Silveira \\ Universidade Federal do Rio Grande do Norte - \\ Departamento de Odontologia \\ Av. Senador Salgado Filho, 1787 - Lagoa Nova \\ Natal, RN - Brasil \\ 59056-000 \\ E-mail: ericka_janine@yahoo.com.br
}

Received: August 11, 2009

Accepted: November 17, 2009

Conflict of Interest Statement: The authors state that there are no financial and personal conflicts of interest that could have inappropriately influenced their work.

Copyright: (C) 2010 Moraes et al.; licensee EDIPUCRS. This is an Open Access article distributed under the terms of the Creative Commons AttributionNoncommercial-No Derivative Works 3.0 Unported License. 


\section{Introduction}

Lichen planus is a chronic inflammatory disease that affects skin and mucosa. It is one of the most common dermatological conditions involving the oral cavity. Its prevalence in the general population is around $1 \%$ to $2 \%$, and there are a large number of cases in females (1-3).

The oral manifestations of lichen planus have been described in the literature and can be classified into 3 types: reticular lesions, including white lines, papules and plaques; atrophic or erythematous lesions; and erosive lesions, including ulcers and bullous lesions. Whereas reticular forms are usually asymptomatic and sometimes discovered during a routine oral clinical examination, the erythematous forms are painful, causing discomfort to the patient $(1,2)$. According to Sousa et al. (3), clinically, oral lichen planus has specific and clearly identifiable features, usually presenting in one of two main forms - the reticular and the erosive forms, although the other forms are not rare.

Since 1869, when the lesion was first described, the etiopathogenesis of the lesion is still uncertain and is a subject of many studies. Sugerman et al. (4) believe that specific and non-specific mechanisms may be involved in the etiopathogenesis. The specific mechanism involves the presentation of antigen by keratinocytes and death caused by cytotoxic $\mathrm{T}$ lymphocytes, and the non-specific mechanism includes degranulation of mast cells and activation of matrix metalloproteinases (1).

Lichen planus has potential for malignant transformation (2), and the risk of malignant transformation varies between 0.4 and $5 \%$ in a period of observation from 0.5 to 20 years (5). However, many controversies remain with regard to the risk of malignant transformation, to the clinical form with the greatest potential for malignancy, and about therapies used for the treatment of OLP (5).

At microscopic examination, the lesion shows an intense inflammatory infiltrate that is predominantly lymphocytic immediately underlying the epithelium and organized into a dense band-like pattern. The epithelium may be acanthotic, and the cells of the basement layer may show hydropic degeneration and loss of continuity (1).

As there is still no definitive treatment for many injuries, drugs have been used to alleviate the painful effects and the size of lesions and thus, to improve the oral health of the patient. The drugs used have local or systemic actions, and their major active components are corticosteroids such as triamcinolone, fluocinolone acetonide and fluocinonida. Elixirs of dexamethasone, clobetasol and triamcinolone are used in patients with oral involvement (6). Aiming to better understand the clinical behavior, the histopathology, and the main treatments for patients with OLP, we propose to present two case reports in male patients and to discuss issues in their management.

\section{Description of the cases}

\section{Case report 1}

A 55-year-old, black, male patient was referred to the Oral Diagnosis service complaining of rough tongue. The patient reported that the change was noted one and a half months earlier. He said that he had painful symptoms during the ingestion of hot foods and that these symptoms had been previously treated with different topical medicines, including myconazol, nystatin solution and benzidamine hydrochloride; however, the lesion did not regress. The subject reported habits of smoking and drinking alcohol beverages. The medical history did not have relevant facts.

At clinical examination, the lesion was localized on the dorsum of the tongue and was of the papular form (Fig. 1A), and other lesions were identified in the left and right buccal mucosa (Fig. 1B) that showed up as white striations; no ulcer was present. The clinical diagnosis was oral lichen planus. For confirmation of this diagnosis, an incisional biopsy of this lesion was requested. An anti-HCV test was also requested, and the result was negative.
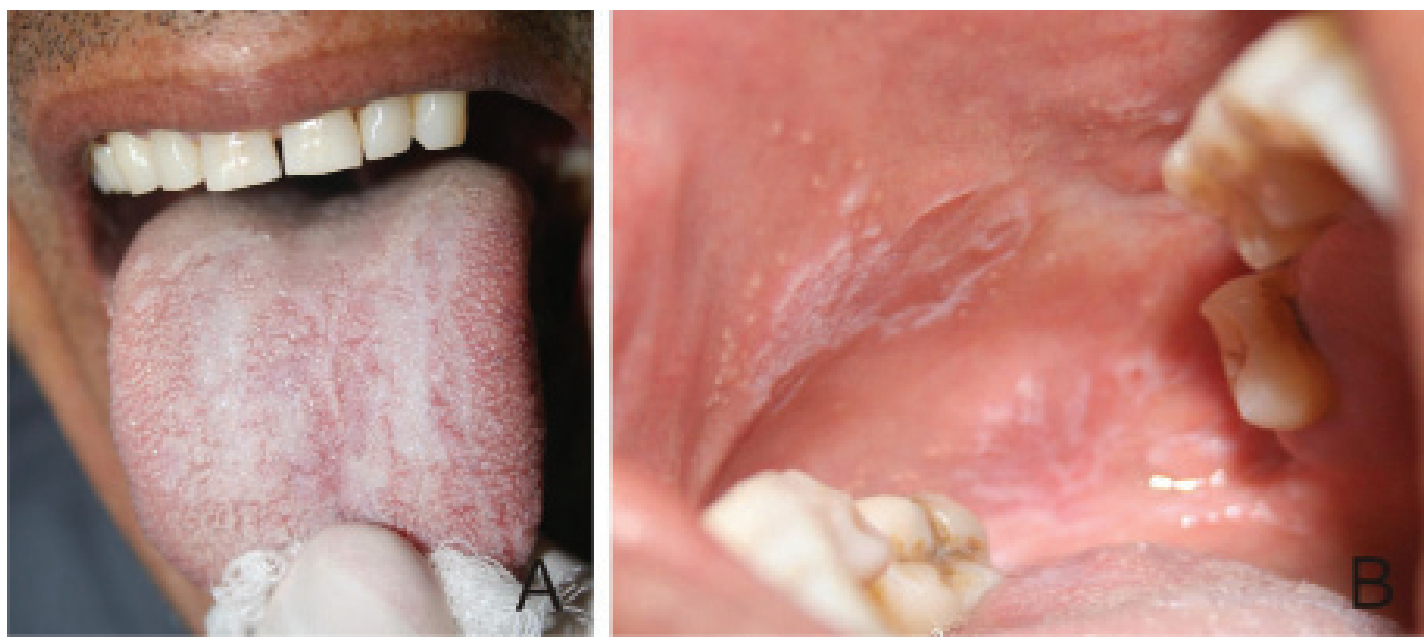

Fig. 1. Lesion in the dorsum of the tongue with papular form $(A)$ and in the right buccal mucosa with white striations (B). 
The histopathological characteristics of the specimen revealed a fragment of oral mucosa lined by stratified squamous epithelium, with areas of ortho or parakeratosis, acanthosis, spongiosis, focus of hydropic degeneration and degeneration of the basement layer. The underlying lamina propria was formed by fibrous connective tissue with variable density and presented an intense inflammatory infiltrate, mainly lymphocytic, situated in the subepithelial region and arranged in a band-like pattern (Fig. 2). For treating the painful symptoms, an elixir of dexamethasone, taken three times a day for 15 days, was prescribed. After 15 days, a decrease in the size of the two lesions was observed, with complete remission of the symptoms observed previously. The patient was asked to come again to the oral diagnosis service in one year in order to follow his progress.

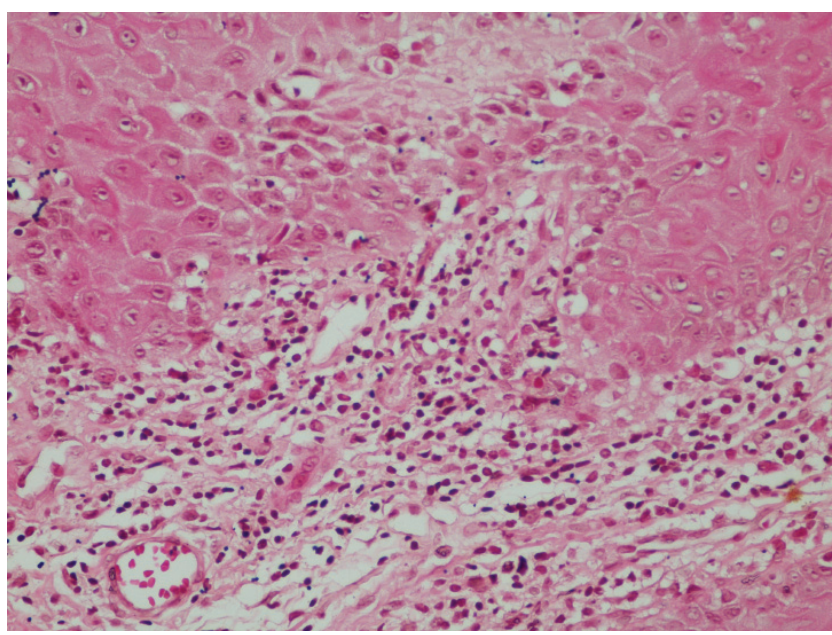

Fig. 2. Photomicrograph showing a lymphocytic infiltrate in band-like pattern (H-E staining $x$ 200).

\section{Case Report 2}

A 42-year-oldmale patient was referred to the Oral Diagnosis service complaining of lip lesions. The patient denied feeling pain; however, he felt esthetically disturbed. He said that the lesion had appeared about three months earlier and that he had been treated with pomade and vitamin B. The previous medical history revealed that the subject suffered from arterial hypertension. At anamnesis, the patient reported having suffered an anger episode and a bought of fidgeting, and he thought that these events influenced the appearance of the lesions. Considering his testimony, his emotional stress was determined to be a potential causal factor to the appearance of the lesions. We requested anti-HCV test, and it was negative.

During the oral clinical exam, the presence of lesions on the lower and upper lips was observed (Fig. 3A); additional lesions were observed on the upper eyelids (Fig. 3B) and on his body, mainly affecting the superior and inferior members (Fig. 3C). These lesions were diverse in size and were white plaque-like with normal consistence from the tissue. The lesions did not show mobility or secondary signals that could be added to the description; no ulcer was present. In view of the facts, the clinical diagnosis was lichen planus, and, in order to confirm the diagnosis by microscopical exam, the patient was submitted to incisional biopsy of the lower lip lesion.

The microscopic findings were the same as those for the previous case, and in focal areas, the presence of basophilic degeneration from collagenous fibers was observed. The patient was treated topically with $0.05 \%$ clobetasol propionate for fifteen days for regression of the lesions. The evaluation of skin lesions was conducted by a dermatologist.
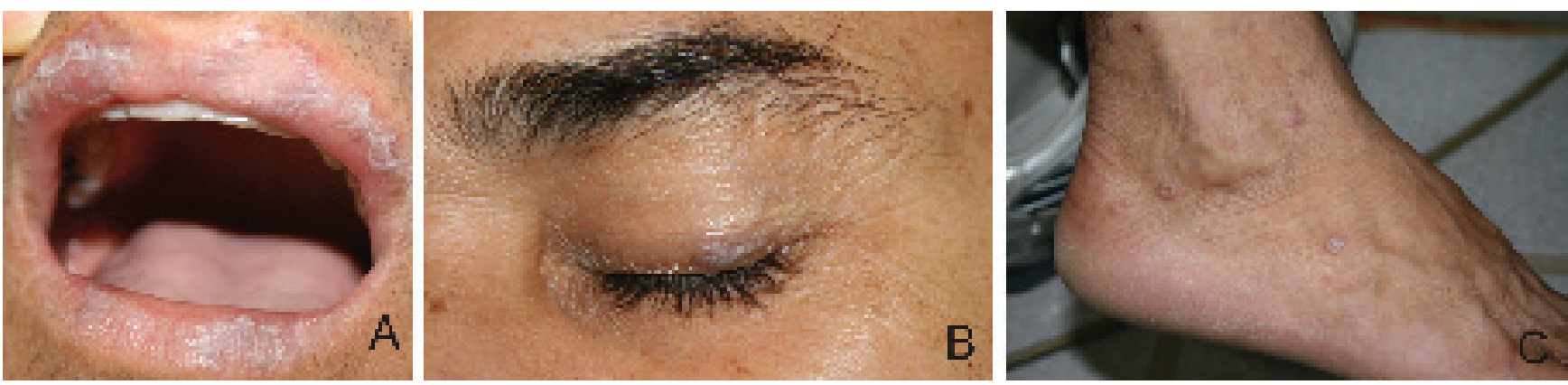

Fig. 3. Lesions in lip (A), upper eyelids (B) and inferior member (C). 


\section{Discussion}

Lichen planus (LP) is a chronic autoimmune disease with an unknown etiology that is marked by the invasion of lymphocytic infiltrate within the epithelial tissue inducing epithelial cell apoptosis and chronic inflammation (5). The main areas involved are the skin and oral cavity, but it can also occur in the vaginal mucous, scalp and nails (5-6). The prevalence of oral lichen planus (OLP) in the general population ranges between $0.5-2.6 \%$ (6). The median age group affected ranges from the third to sixth life decades; the occurrence in children is uncommon, and the disease is more common in females (2). The patients in this case study were males of 55 and 42 years, which fall into the age range in which lichen planus is most commonly reported. The precise etiology of this condition is unknown, but, in their review, Ismail et al. (6) reported a list of causative and exacerbating factors for OLP and oral lichen planus reactions such as, drugs (anti-malarial, diuretics, gold salts, antiretroviral), dental materials (dental amalgam, composite and resin-based materials, metals), chronic liver disease and hepatitis $\mathrm{C}$ virus, genetics and tobacco chewing. In our cases, there were no situations like these that could have provoked oral lichen planus reactions.

There is numerous evidence that cell-mediated immunity, possibly initiated by endogenous or exogenous factors in individuals genetically predisposed to the disease, is crucial for the pathogenesis of the disease. Activated T lymphocytes and increased production of cytokines result in increased expression of the intercellular adhesion molecule (ICAM-1) and the major histocompatibility complex type II by keratinocytes, which leads to tissue destruction. This process results in immune vacuolar degeneration, lysis of cells in the basal layer, and, finally, dissolution of the cells of the basal layer (7).

Stress was identified as one of the most frequent causes of acute exacerbation of the disease $(7,8)$. A recent study suggests that patients with OLP exhibit higher levels of anxiety and depression compared with control groups. In addition to the discomfort that is caused by the lesion, many patients are concerned about a possible malignancy and the contagious nature of the lesion, which is favored by the lack of educational materials available to individuals with the disease. Therefore, the education of patients with OLP can minimize their anxiety (7). In the case of Patient 2, during the anamnesis he reported a change in his emotional condition, and we noticed a certain anxiety in both patients that may be related to the absence of knowledge about the disease.

Six clinical forms of OLP have been described: reticular, papular, plaque-like, erosive, atrophic and bullous $(6,7)$. A more simple clinical classification consists of three types of lesions: reticulated lesions, including rows, plaques and whitish papules; atrophic or erythematous lesions; and erosive lesions, including ulcerations and bullous lesions. Whereas the reticular lesions are asymptomatic, the erythematous and erosive ones induce discomfort (7).
Clinically, the lesions in the oral cavity are usually multiple and bilateral $(5,6,8)$. OLP can involve any place in the oral cavity; however, the main locals involved are the buccal mucosa, gingival and tongue $(6,8)$. The most common clinical presentation is whitish striae in a reticulated pattern $(5,8)$. In the cases presented here, the anatomical areas of the lesion were the back of the tongue, buccal mucosa and lower lip, yonder cutaneous signs. The lesions in the buccal mucosa had a striae shape and were reticulated, whitish, and bilateral, and those from the tongue had a whitish papule shape. The lip lesions were in whitish and purple plaques, and there were whitish plaques on the inferior limbs.

The cases of LP that are restricted to oral mucosa, i.e., with minimal involvement of the skin, occur in $15 \%$ of all cases. Detailed reports of simultaneous occurrence of LP in the oral cavity and skin are uncommon (5). In the patient in Case 2, lesions were identified on the lips and on the skin of the lower limbs. Cases with lichen planus isolated to a single site are rare, (7) and the cases reported in this case study corroborate the literature because the lesions involved multiple sites.

Differential diagnoses include lichenoid eruptions associated with medications, lichenoid lesions associated with contact with restorative materials, leukoplakia, lupus erythematosus and graft versus host disease (GVHD) (6).

The diagnosis of OLP is based on clinical and histopathological findings. Classic histopathologic features include the presence of a lymphocytic infiltrate in the subepithelial region in band-like patterns, liquefactive degeneration of the basal layer, Civatte's bodies, which are the presence of numerous eosinophilic colloid bodies along with interface-epithelial tissue packs, variable degrees of focal ortho or parakeratosis and irregular acanthosis $(7,8)$. The histopathological features were consistent with the diagnosis of lichen planus, as the main findings were the presence of band-like subepithelial lymphocytic infiltration and degeneration of the basal layer.

The management of patients with OLP is very important. The recognition of the form of OLP and its location and questions about the clinical factors that may modify the clinical appearance, such as Candida sp. infection and the use of medications or irritation due to the use of prosthesis, should be evaluated. A regular follow-up of the patient with OLP should be done (8). The choice of treatment depends on the severity and the discomfort. Unfortunately, there is no treatment to permanently resolve the lesions. Drugs are used to improve the condition of the patient. These medicaments may be local or systemic. The active components are corticosteroids such as triamcinolone, fluocinolone acetonide and fluocinonida. An elixir of dexamethasone, clobetasol and triamcinolone has been used in patients with oral involvement (3). The propaedeutic used by our service was the elixir of dexamethasone $0.1 \mathrm{mg} / \mathrm{ml}$ for intra-oral lesions, and clobetasol propionate $0.5 \mathrm{~g} / \mathrm{g}$ in the form of a cream was prescribed for lesions in the lip. The patient with skin manifestations was sent to a medical dermatologist for evaluation and treatment of the skin lesions. 
According to Ismail et al. (6), maintenance of good oral hygiene can enhance healing and lessen symptoms, and exacerbating factors should be minimized or removed. Surgical management, including cryosurgery and carbon dioxide (CO2) laser, has been performed on OLP lesions, but surgical excision is not recommended as the first-choice treatment due to the inflammatory condition, which can recur (6).

An undesirable complication of OLP is the development of squamous cell carcinoma (SCC). Many studies have been focused on this potential malignant transformation of OLP (8), but the potential for malignancy of these lesions is still controversial. The frequency of malignant transformation ranges from 0.4 to $5 \%$, with the highest rates in the erythematous and erosive lesions $(6,7)$.

Krutchkoff and Eisenberg (9) used the term lichenoid dysplasia to describe lesions that resemble OLP but that are dysplastic. Recent study suggests genetic changes such as loss of heterozygosity (LOH) in dysplastic OLP that are also seen in SCC. Zhang et al. (10) found a low loss of heterozygosity $(6 \%)$ in OLP without dysplasia when compared with dysplastic OLP ( $40 \%$ for dysplasia average). These findings support that epithelial dysplasia in OLP is an indication to the risk of malignancy of the lesion (10).

Lichen planus is an autoimmune mucocutaneous disease that does not have an effective treatment and that most frequently causes significant discomfort and pain for the patient. A suitable protocol for lichen planus includes the correct identification of lesions by biopsy and histopathological analysis and the use of anti-inflammatory drugs as a treatment. When lichen planus occurs in the skin, patients should always be referred to dermatologists; in other words, there is a very important role of the multiprofessional actuation to treat lichen planus, and regular clinical monitoring is important because of the risk of malignant transformation reported by some authors.

\section{References}

1. Bornstein MM, Hakimi B, Persson GR. Microbiological findings in subjects with asymptomatic oral lichen planus: a cross-sectional comparative study. J Periodontol 2008;79:2347-55.

2. McCartan BE, Healy CM. The reported prevalence of oral lichen planus: a review and critique. J Oral Pathol Med 2008;37:447-53.

3. Sousa FA, Rosa LE. Oral lichen planus: clinical and histopathological considerations. Braz J Otorhinolaryngol 2008;74:284-92.

4. Sugerman PB, Savage NW, Walsh LJ, Zhao ZZ, Zhou XJ, Khan A, Seymour GJ, Bigby M. The patogenesis of oral lichen planus. Crit Ver Oral Biol Med 2002;13:350-65

5. Scully C, Carrozzo M. Oral mucosal disease: Lichen planus. Br J Oral Maxillofac Surg 2008;46:15-21

6. Ismail SB, Kumar SK, Zain RB. Oral lichen planus and lichenoid reactions: etiopathogenesis, diagnosis, management and malignant transformation. J Oral Sci 2007;49:89-106.
7. Einsen D. The clinical features, malignant potential, and systemic associations of oral lichen planus: a study of 723 patients. J Am Acad Dermatol 2002;46:207-14.

8. Epstein JB, Wan LS, Gorsky M, Zhang L. Oral lichen planus: progress in understanding its malignant potential and the implications for clinical management. Oral Surg Oral Med Oral Pathol Oral Radiol Endod 2003;96:32-7.

9. Krutchkoff DJ, Eisenberg E. Lichenoid dysplasia: a distinct histopathologic entity. Oral Surg Oral Med Oral Pathol 1985;60: 308-15.

10. Zhang L, Cheng X, Li Y, Poh C, Zeng T, Priddy R, Lovas J, Freedman $P$, Daley T, Rosin MP. High frequency of allelic loss in dysplastic lichenoid lesions. Lab Invest 2000;80:233-7. 